\title{
Jogando luzes sobre os determinantes burocráticos e de gestão da política de assistência social nos municípios brasileiros
}

\author{
Natália Guimarães Duarte Sátyro ${ }^{1}$ \\ Eleonora Martins Schettini Cunha² (D)
}

\begin{abstract}
As pesquisas empíricas conhecidas mostram-se insuficientes para explicar a variação da capacidade burocrática e de gestão no nível local e suas consequências para a implementação de políticas sociais. Este artigo analisa a percepção de técnicos e gestores municipais da assistência social quanto aos fatores problemáticos na implementação da política. O desenho de pesquisa utiliza-se de grounded theory, pois o intuito é gerar conhecimento sobre o campo, e de um survey, na tentativa de analisar o quanto os achados qualitativos são representativos do todo. Os resultados mostram a centralidade das limitações orçamentárias na implementação da política, mas põem no centro da discussão fatores técnicos e administrativos como os grandes entraves da gestão da política de assistência social no nível local. Os resultados sugerem também o uso de estratégias informais para a solução de problemas dessa natureza.
\end{abstract}

Palavras chave: assistência social; burocracia do nível de rua; grounded theory; implementação de políticas sociais; capacidade burocrática

\section{Introdução ${ }^{3}$}

A implementação de políticas públicas tem sido objeto de estudos empíricos cada vez mais sofisticados, buscando identificar e melhor compreender os fatores que possibilitam maior ou menor êxito no processo e mesmo nos resultados da política. Diversas características normativas, estruturais, organizacionais e interacionais têm sido apontadas como relevantes para essas análises e, por conseguinte, indicam caminhos diversos para abordagens de pesquisa. Por outro lado, as próprias políticas públicas se tornaram mais complexas, seja em razão da percepção da multicausalidade dos problemas

\footnotetext{
${ }^{1}$ Universidade Federal de Minas Gerais - Departamento de Ciência Política, Belo Horizonte (MG), Brasil. E-mail: <nsatyro@gmail.com>.

2 Universidade Federal de Minas Gerais - Departamento de Ciência Política, Belo Horizonte (MG), Brasil. E-mail: <eleonoraufmg@gmail.com>.

3 Agradecemos o apoio financeiro do CNPq no âmbito da Chamada MCTI-CNPq/MDS-SAGI No 24/2013 Desenvolvimento Social. Deixamos aqui o reconhecimento de que os comentários dos(as) pareceristas da revista Opinião Pública nos permitiram finalizar um texto muito melhor do que o inicial, ainda que a responsabilidade por qualquer conteúdo seja nossa; a eles/elas o nosso agradecimento.
} 
que elas visam enfrentar, seja porque seus desenhos passaram a incorporar diferentes atores institucionais e sociais nos processos de formulação, execução e avaliação, demandando articulações e interações não experimentadas anteriormente.

Esse é o caso da política de assistência social brasileira. Instituída a partir da Constituição Federal de 1988, teve sua normatização iniciada em 1993 e melhorou sua estrutura a partir de 2004. Seu desenho prevê uma organização descentralizada, tendo o Ministério de Desenvolvimento Social (MDS) a responsabilidade por sua formulação e aos municípios cabe executar a maior parte das ações socioassistenciais, sendo que os estados atuam supletivamente aos municípios e em ações regionalizadas. Essas ações são pactuadas por gestores dos três níveis de governo na Comissão Intergestores Tripartite (CIT) e deliberadas no Conselho Nacional de Assistência Social (CNAS), composto por representantes governamentais e da sociedade civil. Esse modelo de organização, denominado Sistema Único de Assistência Social (Suas), aponta para a necessidade de que os municípios estejam estruturados e detenham capacidades técnico-administrativas e políticas para sua efetivação.

Os fatores explicativos apontados na literatura para o êxito na implementação de políticas públicas levantam um conjunto de reflexões para esse processo na política de assistência social brasileira. Orientada atualmente por um paradigma de direito e de responsabilidade do Estado, ela tem uma trajetória marcada pela centralização no nível federal de governo e por práticas clientelistas, fragmentadas e realizadas, predominantemente, por instituições filantrópicas e pouco efetivas em seus resultados. Esse legado representa uma recente (re)organização de estruturas municipais, própria para a implementação da política, e sua correspondente burocracia, processo que foi fortemente induzido pelo nível federal a partir de 2004. Isso se traduz na fragilidade técnica e administrativa de muitos municípios nessa área, o que pode ser percebido pela grande variação dos resultados da implementação da política, identificada nos instrumentos de monitoramento do MDS e em estudos acadêmicos (Sátyro, Cunha e Campos, 2016; D'Albuquerque, 2017; Sátyro e Cunha, 2018; Cavalcante e Ribeiro, 2012; Lotta, Pereira e Bichir, 2018).

Ainda que muito se tenha produzido no que se refere à implementação da política em municípios brasileiros, permanece a necessidade de entender melhor o que acontece no nível local que determina a variação no âmbito municipal. Assim sendo, o objetivo deste artigo é contribuir para uma melhor compreensão dos fatores que influenciam diretamente esse processo, mas, mais do que isso, interessa-nos saber de gestores e técnicos municipais, considerados como agentes implementadores da política, quais são os entraves que eles percebem como relevantes.

Optamos por realizar uma pesquisa exploratória por não encontrarmos estudos com essa mesma finalidade para a política de assistência social. Decidimos por dar voz a gestores e técnicos que trabalham na implementação dessa política nos municípios, de modo a compreender sua percepção quanto aos fatores que dificultam esse processo, ou 
seja, a que eles atribuem as dificuldades encontradas na implementação da política. Para isso, utilizamos uma abordagem fundamentalmente qualitativa (grounded theory) inicialmente realizando entrevistas e grupos focais com gestores e técnicos da política. Para que os resultados pudessem ser tratados com um nível de generalidade maior do que o permitido por essas técnicas, a pesquisa se utilizou de um survey nacional, cujas questões foram formuladas a partir dos grupos focais e entrevistas.

O artigo está organizado em cinco partes, além desta introdução e das considerações finais. A primeira, "Algumas considerações sobre a implementação de políticas públicas", apresenta breves considerações teóricas acerca dos fatores destacados na literatura como relevantes para o estudo da implementação de políticas públicas. A segunda, "Considerações metodológicas: perguntando a quem sabe", expõe o percurso metodológico. A terceira, "Dando voz a gestores e técnicos municipais de assistência social", apresenta e analisa os dados primários derivados de entrevistas e grupos focais. Na quarta parte, "Ampliando as vozes", são apresentados alguns resultados do survey. Na quinta, "Daquilo que não foi perguntado, mas foi achado", tecemos breves considerações sobre o que emergiu nesse percurso. Por fim, considerações são feitas sobre os resultados à luz de algumas categorias analíticas destacadas na literatura.

Os resultados mostram que, tanto quanto as limitações orçamentárias, os fatores técnicos e administrativos são determinantes na implementação da política de assistência social no nível local. A interação dinâmica entre fatores relacionados à organização do aparato administrativo e aos atores e suas interações para a resolução de problemas cotidianos mostrou-se significativa para explicar a capacidade de gestão (e consequente implementação) das políticas no nível municipal, mesmo em condições financeiras e administrativas adversas.

\section{Algumas considerações sobre a implementação de políticas públicas}

O campo de estudos das políticas públicas fez um importante deslocamento de foco das estruturas e normas do Estado em direção às dinâmicas e aos fluxos de seu funcionamento, ou seja, às características das agências públicas, atores, inter-relação entre instituições e atores, aspectos contextuais que influenciam as ações governamentais, dentre outras características. Esse movimento foi acompanhado pela formulação de diferentes conceitos de políticas públicas (Lowi, 1964; Lasswell, 1971; Lynn, 1980; Dye, 1984; Mead, 1995) e pelo desenvolvimento da compreensão destes como um processo que envolve decisões e ações estratégicas voltadas à solução de problemas públicos sob a responsabilidade governamental e que, por conseguinte, aloca recursos públicos. Como processo, envolve um conjunto de atores, com seus valores e ideias, em diferentes estágios, desde sua formulação, quando são elaboradas prescrições normativas e se organizam as estruturas e correspondentes funções que vão efetivar as políticas públicas até sua conclusão (Saravia e Ferrarezzi, 2006). 
Assim compreendidas, as políticas públicas são potencialidades que podem ou não ser realizadas. Isso porque sua implementação é um processo bastante dinâmico, que envolve interações contingentes entre diferentes atores (do Estado e da sociedade), contextos diversos e mesmo a agência de implementadores, o que significa que a execução de uma política pode gerar adaptações circunstanciais e mesmo sua reformulação (Majone e Wildavsky, 1984; Hill, 2006).

A percepção da relevância da implementação para os resultados das políticas públicas tem gerado maior ênfase na sua análise (Faria, 2012), por meio de distintas abordagens. Na literatura é possível encontrar dois modelos analíticos principais: um focado na estrutura técnico-administrativa, que implementa as ações previamente definidas no momento da formulação, e o outro centrado nos atores e na capacidade do Estado, o que aponta diretamente para o papel da burocracia. Na primeira abordagem, assinala-se um conjunto de variáveis consideradas como relevantes para o seu êxito, como aquelas relacionadas à natureza da política, às normativas que a orientam (inclusive a disponibilidade de recursos), os contextos (sociais, políticos e econômicos) e a organização do aparato administrativo (disponibilidade e qualidade dos recursos humanos e estrutura organizacional). A segunda abordagem considera que o êxito está condicionado pela capacidade dos atores e suas interações, destacando a discricionariedade como fator relevante (Lipsky, 1980; Walt, 1994; Howlett e Ramesh, 1995; Elmore, 1996; Van Meter e Van Horn, 1996; Sabatier e Mazmanian, 1996; Collins e Makowsky, 1998; Lowndes, 2002; Christiansen e Piattoni, 2003; Lima e D'Ascenzi, 2013).

Lima e D'Ascenzi (2013) somam aos fatores já destacados na literatura os aspectos culturais (cognitivos e ideológicos) que incidem na ação, compreendendo a implementação como um processo que resulta da interação entre a intenção do que foi planejado e o contexto local, mediado por ideias e visões de mundo dos atores. Nessa perspectiva, as normas que estruturam a política são efetivadas em contextos que levam a adaptações conforme as capacidades dos governos e das suas burocracias, indicando a importância da disponibilidade e qualidade dos recursos humanos e materiais, da estrutura e regras organizacionais (formais e informais) e do fluxo e disponibilidade de informações. Também destacam a relevância das ideias e percepções que os atores têm da política e suas especificidades.

A compreensão de que a burocracia em interação entre si e com os usuários da política tem importante papel na sua condução e execução, bem como nos seus resultados, tem gerado construções teóricas e analíticas acerca desses agentes e suas ações. A literatura distingue os burocratas conforme sua posição nas estruturas do Estado e seu pertencimento a carreiras: os de alto e médio escalão e os de nível da rua. Os primeiros são recrutados para carreiras consideradas de elite e situam-se em posições estratégicas, atuando fortemente no processo de formulação das políticas; os segundos são dirigentes que desempenham função intermediária e que gerenciam a burocracia do nível da rua, 
esta constituída pelos profissionais que executam a política diretamente (Oliveira e Abrúcio, 2018; Lotta, Pires e Oliveira, 2014; Cavalcante e Lotta, 2015).

Os estudos sobre burocracia de alto e de médio escalão, de modo geral, associam a condição de burocratas à de dirigente público, ou seja, analisam a burocracia que ocupa funções de direção e de comando na administração pública, nos chamados "cargos de confiança", especialmente no nível federal. Poucos estudos tratam do nível estadual e menos ainda do nível municipal. Isso nos impõe algumas reflexões importantes, uma vez que pesquisas qualitativas necessitam precisar e ajustar categorias conceituais (Mahoney e Goertz, 2006). A primeira é a necessária distinção entre burocracia e dirigente público: a burocracia é constituída pelo corpo permanente e não eleito do Estado, conforme carreiras previamente definidas; dirigente público ocupa funções de direção em cargos comissionados, com a responsabilidade pelos resultados da política, situando-se entre o político eleito e a burocracia, podendo ser recrutado no círculo político do mandatário ou dentre os burocratas de carreira. Sua posição de gestão está associada a um alto poder de discricionariedade (De Bonis e Pacheco, 2010).

Burocratas e dirigentes públicos estão presentes nas estruturas administrativas dos três níveis de governo. Podemos entender, portanto, que há dirigentes de "alto escalão", situados no topo da gestão, aos quais cabe tomar decisões estratégicas e responder diretamente pela política pública, seja ao mandatário político, seja à sociedade. Os dirigentes de "médio escalão" desempenham papel técnico-gerencial - em que "traduzem determinações estratégicas em ações cotidianas nas organizações, construindo padrões de procedimentos e gerenciando os serviços" (Lotta, Pires e Oliveira, 2014, p. 472) - e técnico-político - em que "constroem negociações e barganhas relacionadas aos processos em que estão envolvidos e sua relação com o alto escalão" (p. 472). Por estarem em posição intermediária, exercem influência "para cima", com o alto escalão, quando priorizam alternativas e sintetizam informações, e "para baixo", com a burocracia de nível da rua, quando facilitam adaptações e implementam estratégias deliberadas. O estudo de Lima et al. (2014) evidencia que os que atuam na função de coordenação e interagem com executores, burocracia de alto escalão e usuários têm papel relevante no processo de adaptação da política.

Soma-se a isso a reflexão que está relacionada à estruturação do Estado brasileiro e à descentralização de suas políticas públicas. O nível federal é responsável pela formulação e coordenação da política, o que ocupa prioritariamente seus dirigentes e burocratas, cabendo aos estados e municípios a implementação da política e a coordenação de ações, definidas nacionalmente, na sua esfera. Assim sendo, a diferenciação das atribuições no ciclo da política pública conforme o nível de governo aponta para atribuições comuns, mas também distintas tanto para os dirigentes quanto para as burocracias. No âmbito local, a proximidade com os cidadãos e a necessidade de realizar entregas coloca desafios concretos para a efetivação da política. 
Estudos sobre a burocracia de nível da rua (BNR) - profissionais de diferentes formações que interagem diretamente com os usuários - mostram que ela tem papel fundamental na implementação de uma política, adaptando-a conforme os contextos em que operam. Também nela é identificada a discricionariedade nas decisões e ações cotidianas, que tanto pode contribuir para a adequação da política à especificidade local quanto alterá-la substancialmente e mesmo restringir acessos de possíveis beneficiários. Considera-se que isso pode decorrer do caráter profissional da atuação, do limite de recursos, de restrições na capacidade de supervisão e controle, de fatores cognitivos, bem como da ambiguidade dos objetivos e estratégias da política (Lipsky, 1980; Brodkin, 2007; Lotta, 2012; Gofen, 2014, apud Lima et al., 2014). A questão, portanto, é como essa discricionariedade ocorre e quais suas consequências para a trajetória, o desenho e os resultados da política.

A implementação, portanto, envolve um complexo encadeamento de interações de distintos atores, que possuem valores que orientam suas ações e decisões e que se situam em posições diferentes, em diversas instituições e níveis hierárquicos, tomando decisões e realizando adaptações na política, gerando uma cadeia de transformações (Lotta e Pavez, 2010). Evidenciam-se desde aqueles que detêm posições de comando e gerência até os que efetivamente realizam as entregas. Lotta (2014) destaca o papel da cadeia de agentes envolvidos no processo de implementação e a relevância de fatores relacionais nos processos de implementação (sejam os vínculos entre profissionais e usuários, sejam as trajetórias sociais e relacionais dos implementadores), bem como dos fatores institucionais (estruturas de comando, normas locais, diretrizes institucionais, processos de trabalho estabelecidos localmente).

A implementação de políticas públicas, portanto, inclui ações que vão além dos procedimentos burocráticos. Seguindo Lipsky (1980), os BNR se utilizam de estratégias e mecanismos inventados por eles para lidar com as incertezas e pressões de seu trabalho e que são próprias da política pública em questão. A discricionariedade, portanto, não só é esperada, como desejável (Eiró, 2017), sendo utilizada para uma adaptação criativa das regras (Rice, 2012, apud Eiró, 2017) para uma melhor adequação à realidade. Escolhas alocativas e adaptações baseadas em valores e referenciais próprios, por sua vez, geram resultados diferenciados no processo de implementação de políticas. Essa heterogeneidade pode ter consequências menos ou mais positivas quando se pensa na equidade de acesso a serviços públicos, especialmente quando há contextos com fortes desigualdades sociais e segregação espacial (Lotta e Pavez, 2010). As escolhas dos profissionais que implementam as políticas podem contribuir para a diferenciação territorial das ofertas, reforçando ou combatendo processo de segregação e desigualdade (Torres et al., 2008, apud Lotta e Pavez, 2010).

Essa é uma questão que nos parece relevante, se considerarmos que a política de assistência social brasileira está organizada de forma descentralizada, cabendo a 
implementação, em grande medida, aos governos municipais ${ }^{4}$. A complexidade de seu desenho, aliada às variações nos contextos locais e nas capacidades dos municípios, aponta para um grande desafio de implementação. Pires e Gomide (2014) chamam atenção para a importância de que se aliem as capacidades técnico-administrativas (habilidades para levar a efeito as políticas por meio de ações coordenadas e orientadas à geração de resultados) e as capacidades políticas (inclusão de atores diversos e de negociação e condução de processos decisórios compartilhados) nos diferentes níveis de governo para que a implementação alcance resultados satisfatórios. Os autores identificaram que variações nessas capacidades produzem resultados que variam de políticas eficazes e com legitimidade a políticas ineficazes e sem elementos legitimadores, sejam técnicos ou políticos.

Nosso estudo se alia aos esforços de melhor compreensão dos fatores que incidem na implementação de políticas públicas, em especial o papel de atores responsáveis pela implementação e o uso da discricionariedade para a produção de rotinas organizacionais informais que embasam suas ações (Lipsky, 1980). Estudos sobre a implementação da assistência social apontam a importância desses atores, especialmente da BNR, nesse processo e dos fatores cognitivos e discricionários, que o afetam e produzem variações locais (Eiró, 2017; Lima e D’Ascenzi, 2017; Natalino, 2017; Lotta, Pereira e Bichir, 2018). Nosso interesse foi compreender a percepção desses atores sobre as dificuldades que consideram relevantes para implementar a política de assistência social nos municípios, considerando a diversidade das condições administrativas e políticas. Também interessanos conhecer as adaptações utilizadas por eles para efetivar a execução da política, dado que "condições organizacionais moldam as práticas dos atores" (Brodkin, 2011, apud Lima et al., 2014). Portanto, nosso foco é nos atores locais que implementam a política, sujeitos a variações nas condições técnicas, administrativas e políticas (Hupe, 2014, apud Lima et al., 2014; Lotta e Pavez, 2010). Por fim, cabe dizer que há uma significativa produção recente sobre implementação de várias políticas sociais que tem contribuído para ampliar e aprofundar o conhecimento na área, com discussões teóricas e/ou análises empíricas (Faria, 2012; Lima et al., 2014; Pires, 2017). Este artigo, focado na assistência social, acrescenta a esse conhecimento a perspectiva dos profissionais da área.

\section{Considerações metodológicas: perguntando a quem sabe}

O desenho da pesquisa foi pensado para explorar a percepção da burocracia municipal, representada pelos técnicos (os chamados burocratas de nível da rua) e gestores municipais (dirigentes públicos), quanto às dificuldades cotidianas no processo de implementação da política, e, sendo assim, apontou para a utilização do método

\footnotetext{
${ }^{4}$ Atualmente existem muitos trabalhos que analisam a política nacional de assistência social, diferente de uma década atrás. Como nosso foco não é a assistência social enquanto política, sugerimos, dentre outros, o livro organizado por Couto et al. (2017).
} 
denominado grounded theory. Partindo do pressuposto de uma pesquisa indutiva, a teoria fundamentada em dados (TFD) visa abertamente gerar conhecimento e fazer pesquisa ao mesmo tempo, segundo Glaser (1978). Ela nos permite entender os processos políticos dentro das estruturas institucionais dominantes que podem ocasionar grande parte da variação de comportamento em uma dada situação, determinando nesse caso, a execução da política.

Esse desenho tem sua força quando a teoria existente não dá suporte suficiente para entender determinados fenômenos ou ainda quando há pouco conhecimento sistematizado, como é o caso do nosso objeto de análise, em que o elemento cognitivo é pouco abordado em pesquisas que têm o mesmo foco. Em geral, ele é mais utilizado para casos em que há foco em experiências subjetivas e, neste artigo, a TFD foi utilizada como forma de captar a percepção quanto aos entraves, de várias naturezas, à implementação da assistência social nos municípios, e, dentre eles, aqueles relacionados à burocracia municipal são considerados como determinantes.

A estratégia adotada foi dar voz aos sujeitos que concretizam a política, o que nos distancia de categorias analíticas abstratas e nos leva a problemas concretos. Para isso, numa primeira abordagem, realizamos 12 entrevistas semiestruturadas com gestores municipais de assistência social de dez municípios de pequeno porte e dois de médio porte das regiões Norte (Pará, Rondônia e Roraima), Nordeste (Pernambuco e Sergipe), CentroOeste (Goiás) e Sudeste (Minas Gerais). As entrevistas foram realizadas durante o encontro do Colegiado Nacional de Gestores Municipais de Assistência Social, em Cuiabá (2014), de maneira não aleatória, mas procurando diversos perfis que aqui descrevemos. Das entrevistadas, somente três eram primeiras-damas, o que mostra uma tendência importante no sentido de alteração de um padrão anterior, em que prevalecia o primeirodamismo. No entanto, apenas uma das entrevistadas ocupava cargo efetivo e a formação profissional era bastante variada (de assistente social a comerciante e farmacêutica). Cinco delas tinham menos de três anos de experiência no Suas, três tinham entre quatro e dez anos e quatro tinham mais de 20 anos. Quanto à gestão, nove estavam na primeira gestão, duas na segunda gestão e uma tinha 20 anos de experiência. Todas participavam do conselho municipal, uma participava de um consórcio intermunicipal e duas eram presidentes do Colegiado de Gestores Municipais de Assistência Social nos seus estados. Como pode se observar, a amostra não é aleatória e tenta abarcar diferentes realidades e experiências na intenção de saber o quanto os problemas permanecem ou mudam no nível aqui analisado quando trabalhamos com diferentes contextos e profissionais.

As impressões inicialmente colhidas com essas entrevistas puderam ser reafirmadas e confrontadas com as opiniões de gestores e técnicos de 15 municípios de pequeno porte, seis de grande porte e um de metrópole de Minas Gerais, reveladas por meio da realização de quatro grupos focais, em 2014, por ocasião da sua participação em cursos do Capacita Suas. Participaram dos grupos 15 gestores municipais, dois técnicos de referência, três coordenadores, um secretário adjunto e um assessor. Dos participantes 
dos grupos focais, oito informaram o tempo de atuação na assistência social: cinco tinham entre quatro e dez anos de experiência e três tinham mais de dez anos. Apenas quatro ocupavam função de gestão, sendo três deles há cerca de um ano e um por três anos. Nesses casos, evidenciam-se a maior experiência na atuação técnica e a pouca experiência na gestão, muito similarmente ao perfil dos entrevistados anteriormente.

Tendo conhecimento desse conjunto de informações fornecidas por gestores e técnicos municipais e com o objetivo de verificar em que medida esses resultados se reproduziriam no conjunto dos municípios brasileiros, foi realizado um survey nacional com gestores e técnicos municipais, convidados a responder a um questionário eletrônico autoaplicado, com questões fechadas e abertas. Este ficou disponível via Google docs por um período de 60 dias, entre os meses de março e abril de 2015.

Convites foram enviados por e-mail para 1.698 técnicos e gestores dos municípios mineiros, fornecidos pela Secretaria de Estado de Trabalho e Desenvolvimento Social (Sedese), e para 5.486 e-mails do cadastro de gestores dos fundos municipais, cedido pelo MDS. Retirados os duplicados, alcançamos 4.010 e-mails, sendo 2.267 das secretarias e 1.743 diretos dos dirigentes. Considerando os dois conjuntos, totalizamos 5.708 destinatários e obtivemos 1.452 respostas. Também aplicamos 297 questionários como pré-teste em evento organizado pela Sedese e Cogemas, realizado em Belo Horizonte no dia 5 de abril de 2015. O Gráfico 1 nos permite visualizar que 1.206 (69\%) dos respondentes são pertencentes ao que consideramos como dirigentes públicos (secretários, gestores, diretores, assessores, coordenadores, conselheiros), sendo os demais $31 \%$ (533) considerados como burocratas de nível da rua (técnicos dos serviços e da gestão, psicólogos, assistentes sociais, secretário executivo de Conselho) ${ }^{5}$. Isso nos possibilita observar se a burocracia do nível de rua tem uma percepção dos problemas distinta daqueles burocratas em posição intermediária.

\footnotetext{
5 Importante destacar que na amostra do survey o número de gestores supera o de técnicos, mas na população ocorre o inverso, ou seja, o número de técnicos é muito maior que o de gestores. Assim, há uma maior probabilidade de a amostra ser mais representativa do primeiro grupo que do segundo. No entanto, como se verá mais adiante, há uma significativa convergência de percepções e de opiniões entre os dois grupos.
} 
Gráfico 1

Principal função dos respondentes

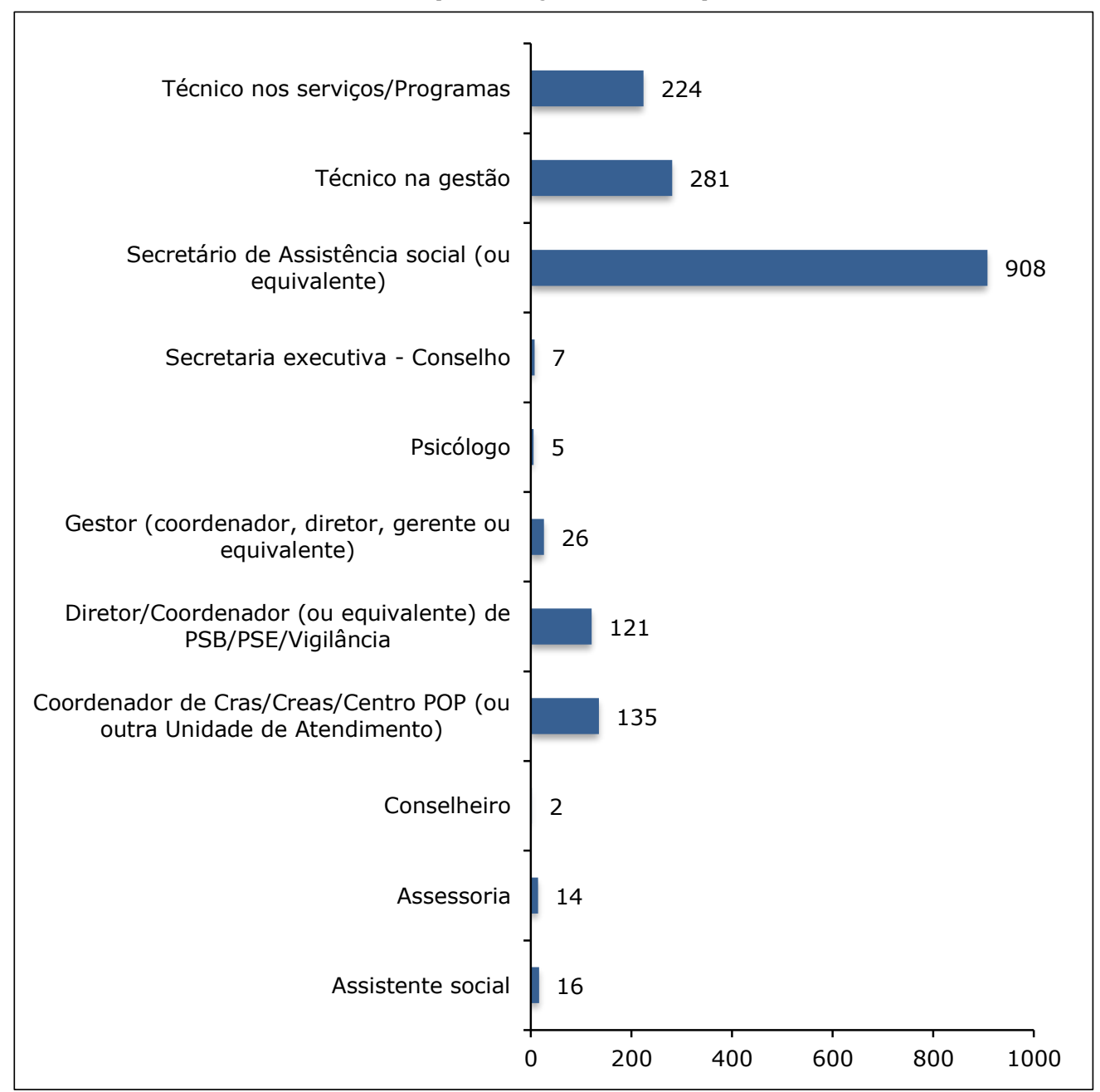

Fonte: Elaboração própria a partir dos dados citados.

Após realizadas as adequações do banco, restaram 1.742 questionários respondidos, sendo que quase todos os estados tiveram algum patamar de resposta (exceto Amapá), como pode ser visto no Gráfico 2. Os municípios estão distribuídos em $56,5 \%$ (984) da região Sudeste, 19,6\% (342) do Nordeste, 11,4\% (198) do Sul, 6,3\% (110) do Norte e 6,2\% (108) do Centro-Oeste. Os respondentes representam 1.357 municípios, 24,36\% do total de municípios brasileiros, sendo 492 de Minas Gerais e 856 dos demais estados. Como no caso de Minas Gerais o questionário foi enviado não somente para os gestores, mas também para os técnicos, há número mais expressivo de respondentes desse estado. 
Gráfico 2

Número de questionários e municípios, segundo a UF

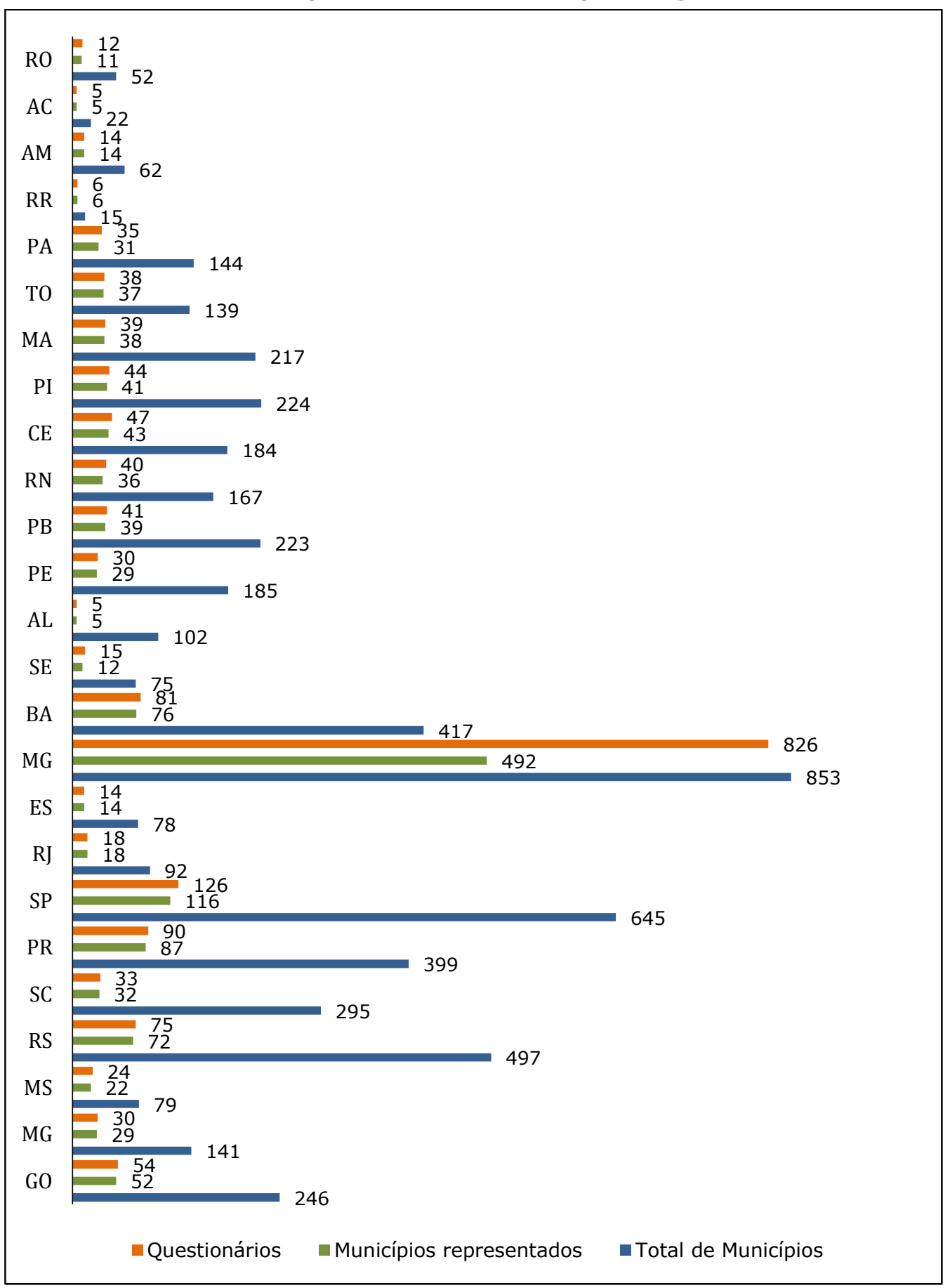

Fonte: Elaboração própria a partir dos dados citados. 
Quanto ao tamanho da população, há representatividade de todos os portes de municípios. No Gráfico 3 é possível comparar o número de municípios que fizeram parte do survey em relação ao número de municípios com um determinado porte populacional: são $22,45 \%$ de municípios com menos de 5.000 habitantes, $25,51 \%$ dos municípios com 5.001 a 10.000 habitantes, $24,4 \%$ com 10.001 a 20.000 habitantes, $24,44 \%$ com 20.001 a 50.000 habitantes, $25,37 \%$ com 50.001 a 100.000 habitantes, $25,77 \%$ com 100.001 a 500.000 habitantes e 33,33\% acima de 500.001 habitantes, somando ao todo 1.357 representados, o que evidencia o quanto a amostra é representativa de cada faixa.

\section{Gráfico 3}

\section{Municípios respondentes por porte populacional}

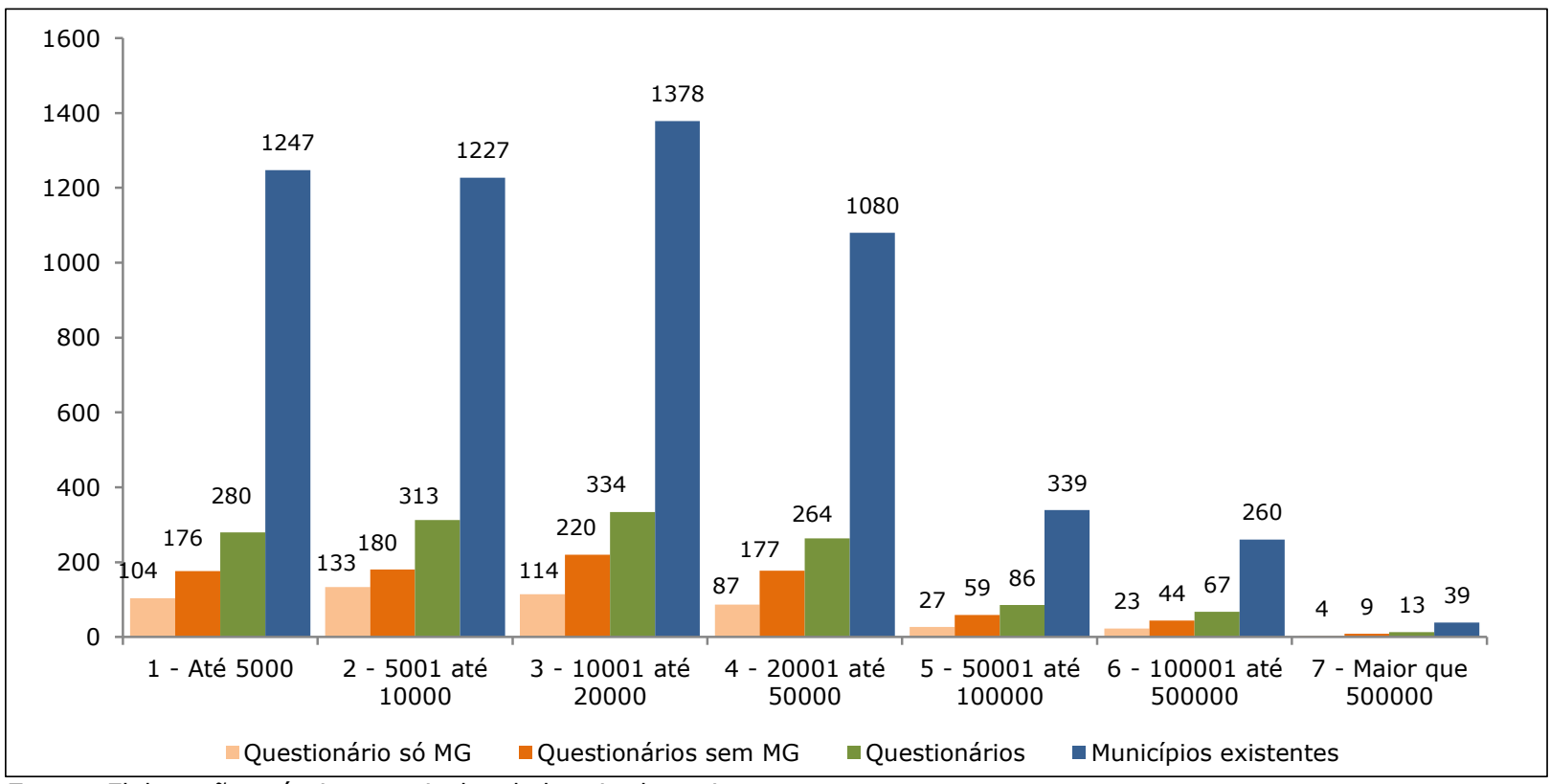

Fonte: Elaboração própria a partir dos dados citados acima.

O conjunto constituído pelos 1.742 respondentes está assim distribuído, conforme porte dos municípios: $19,1 \%$ (333) com menos de 5.000 habitantes, 22,9\% (399) com 5001 a 10.000 habitantes, 23,2\% (405) entre 10.001 e 20.000 habitantes, 19,6\% (341) entre 20.001 e 50.000 habitantes, 8\% (139) entre 50.001 e 100.000 habitantes, 5,7\% (99) entre 100.001 e 500.000 habitantes e 1,5\% (26) acima de 500.001 habitantes.

Cabe ainda uma ressalva com relação à quantidade de respondentes dos municípios mineiros. Numa pesquisa quantitativa, esse número mais expressivo poderia ser visto como uma sobrerrepresentação do estado. No entanto, esses dados nos permitem uma maior representatividade dos técnicos. Do total de respondentes, 542 são técnicos, 1.197 são gestores e 3 não responderam sobre a função. Dentro do total de técnicos, 288 são de Minas Gerais, especificamente, enquanto a outra metade (254) está espalhada 
pelos demais estados. Ademais, os questionários aplicados em Minas Gerais seguem uma mesma distribuição por porte populacional, não enviesando a representatividade dos municípios. No entanto, na medida em que o survey não foi feito de forma amostral e sim por adesão, não podemos falar de representatividade stricto sensu. Porém, isso acrescenta capacidade analítica ao estudo na medida em que permite uma comparação entre técnicos e gestores, principalmente pelo fato de Minas Gerais ser um estado extremamente heterogêneo em termos sociais e econômicos, permitindo algum grau de generalização.

\section{Dando voz a gestores e técnicos municipais de assistência social}

A análise do conteúdo das entrevistas ${ }^{6}$ e dos grupos focais nos levou a classificar os fatores que impactam a implementação da política de assistência social entre componentes sistemáticos e não sistemáticos, conforme estudo de King, Keohane e Verba (1994), que consideram os primeiros como características ou elementos fundamentais e previsíveis do fenômeno estudado, enquanto os segundos são elementos ou eventos ocasionais, e que, portanto, não fazem parte do cenário habitual. Cabe ao pesquisador identificá-los para que possa construir inferências válidas, mesmo quando se trata de um estudo descritivo e exploratório (King, Keohane e Verba, 1994, p. 56).

Primeiramente, na percepção dos atores, há uma miríade de problemas não sistemáticos de diversas naturezas - desde questões políticas, estruturação no nível local, contextos, até aquelas relativas aos atores e sua compreensão e visão sobre a assistência social. Aqui se encontram aqueles que apontam mudanças como a desvinculação da gestão da assistência social de outras áreas de políticas (como saúde), a estruturação da política (como a exigência de planos, fundos e conselhos), sua profissionalização (nesse caso, o destaque é para a Norma Operacional Básica de Recursos Humanos - NOB-RH, que determina os profissionais que devem compor as equipes das unidades públicas).

Essas percepções apontam para a relevância das normativas que orientam a estruturação da política, incidindo diretamente na sua implementação. Somam-se a isso mudanças que não estão relacionadas às normativas, como alterações na percepção dos usuários quanto à assistência social colocando-a, no patamar dos direitos, tornando-os usuários mais independentes em relação aos gestores e técnicos. Entretanto, apontam algumas persistências que influenciam a gestão, como a cultura assistencialista, o primeiro-damismo (ou o cônjuge como secretário da pasta), a dificuldade em efetivar mudanças estruturais no município e de transformar o que está na lei em realidade, bem como o fundo não ser gerenciado pelo gestor da assistência social. Essas percepções

\footnotetext{
${ }^{6}$ As entrevistas gravadas encontram-se em poder das autoras. Caso algum pesquisador tenha interesse em realizar pesquisa a partir dessas fontes, deve procurar as autoras e, mediante projeto e termo de compromisso, poderá ter acesso ao material.
} 
evidenciam aspectos culturais (cognitivos e ideológicos) e contextuais como relevantes para a compreensão da implementação da política no nível municipal.

Os entrevistados foram confrontados e demandados a falar das dificuldades do dia a dia e, mais especificamente, sobre aquelas que, de fato, travam processos, impossibilitando determinadas ações, como a não execução de recursos já disponíveis7, para chegarem aos fatores mais sistemáticos. Nessa perspectiva, evidenciaram-se como sistemáticos aqueles relacionados aos recursos humanos, à gestão orçamentária e financeira e à produção de dados e informações. Em relação aos recursos humanos, a maior parte dos municípios tinha muitos obstáculos para recrutar profissionais para a assistência social, seja pela inexistência deles ou pelos salários pouco atrativos. Há predomínio de recrutamento por processos seletivos amplos, gerando vínculos celetistas ou temporários e grande rotatividade de trabalhadores em alguns municípios. A situação era muito mais grave em cidades da região Norte, onde inexistem ou existem poucos profissionais com formação conforme dispõe a NOB-RH. No caso da existência de concursados, não eram específicos da assistência social, uma vez que os gestores utilizaram profissionais disponíveis no município. A principal consequência disso é a caracterização de vínculos contratuais precários na área, o que gera, por sua vez, a contratação de pessoas com pouca experiência e/ou pouca qualificação para trabalhar no Suas, bem como grande rotatividade de pessoal (o que pode ser visto em Sátyro, Cunha e Campos, 2016).

Dadas as exigências normativas quanto à constituição das equipes técnicas, os entrevistados apontaram que a prioridade era no sentido de compô-las no Centro de Referência da Assistência Social (Cras) e Centro de Referência Especializado da Assistência Social (Creas), e, nesse sentido, os arranjos são os mais diversos para efetivar o funcionamento dos equipamentos no período integral - desde pagar hora extra aos profissionais para que completem as 40 horas até contratar duas equipes de 20 horas cada, o que implica dividir o profissional com outra secretaria ou ter profissionais que trabalham simultaneamente em mais de um município. Ainda assim, a maior parte dos entrevistados considerava que suas equipes eram pouco preparadas para atuar, gerando equívocos na prestação dos serviços, continuidade de práticas inadequadas e resistência às inovações. Portanto, se, por um lado, as normativas contribuíram para a estruturação da burocracia, por outro lado, os aspectos contextuais e culturais que nela incidem aparecem como limitadores para a melhor implementação da política, o que reforça a relevância dos fatores relacionados à estruturação do aparato administrativo.

O foco nos Cras e Creas, ou seja, em atividades finalísticas, fez com que as funções de gestão estivessem pouco estruturadas na maior parte das secretarias e com poucos

\footnotetext{
7 Tomamos a execução orçamentária como fator que possibilita a verificação da capacidade de gestão, uma vez que a implementação da política depende de forma muito expressiva de habilidades e competências para realizar o gasto público, como o conhecimento das regras, a articulação entre setores governamentais, a realização de formas diferenciadas de licitação, entre outras. Assim, entendemos que esta é uma função que demanda aptidões burocráticas específicas, ainda que haja fragilidade nos vínculos de trabalho.
} 
profissionais - há secretarias em que as atividades de gestão da política são realizadas pelo gestor e um secretário administrativo ou assessor. Soma-se a isso o fato de que os cargos de direção são de decisão do prefeito, o que implica não haver pessoal preparado, por exemplo, para coordenar a Proteção Social Básica ou mesmo para realizar o planejamento municipal da área (nas entrevistas individuais, por exemplo, foi-nos revelado que nenhum dos municípios possuía diagnóstico para a área). Isso evidencia que o problema não se restringe à rotatividade e aos vínculos frágeis como características dos profissionais da gestão municipal, mas também a problemas relacionados ao conhecimento necessário para implementar a política.

No que diz respeito às dificuldades orçamentárias e financeiras, mesmo com alguns dos entrevistados revelando que não eram informados sobre os recursos municipais para a política ${ }^{8}$, muitas foram as dimensões colocadas, principalmente nos grupos focais. 0 primeiro problema comum foi a centralidade do papel do contador responsável por dar forma à Lei Orçamentária Municipal, sendo um personagem que pode tanto facilitar e agilizar o processo como pode travar o orçamento da política por mais de um ano. Foi destacada a dificuldade de alguns municípios em executar o recurso disponível advindo do governo federal, por exemplo. Os entrevistados ressaltaram que os contadores, sejam os oriundos da própria prefeitura, sejam os que são externos e prestam serviços aos municípios, muitas vezes não entendem sobre a política e menos ainda sobre as suas especificidades, originando equívocos nas rubricas da área para o Plano Plurianual Governamental e/ou a Lei Orçamentária Municipal. Em alguns casos isso se agrava, pois contadores resistem em fazer alterações em suas formas de trabalho, comprometendo o planejamento adequado da utilização dos recursos disponíveis, gerando um falso superávit. Assim, mesmo que parte da literatura mostre claramente que não é possível afirmar em termos de grandes tendências que capacidade se relacione positivamente com execução (como em Sátyro, Cunha e Campos, 2016), em algum grau isso ainda permanece em aberto, e este artigo, além de buscar conhecer alguns fatores que são percebidos pelos próprios implementadores como relevantes, joga luzes sobre como isso acontece.

Ainda que o contador tenha papel importante no processo de planejamento orçamentário-financeiro, essa não é prerrogativa exclusiva dele, pois o desconhecimento do gestor acerca das regras orçamentárias e das especificidades da política também aparece como relevante. Os grupos concordaram que isso era ainda mais forte nos casos em que o ocupante da pasta não tem trajetória na área ou pouca (ou nenhuma) experiência de gestão, apenas compondo a equipe de governo por questões político-partidárias. Isso gera tensões de ordem político-institucional que muitas vezes emperram a efetivação da

\footnotetext{
8 Há municípios em que essa informação sobre os recursos disponíveis para a assistência social é de conhecimento do prefeito e/ou do secretário de finanças e eles liberam os recursos quando necessário. Isso ocorre mesmo quando o recurso está no Fundo Municipal de Assistência Social, pois eles fazem a gestão do Fundo e não o gestor da AS, como determinam as normas da área. Dentre as respondentes, só três eram ordenadoras de despesa.
} 
implementação e dificulta ainda mais o planejamento da política, restringindo-a a ações imediatas $^{9}$. Se considerarmos que uma política pública só se efetiva se houver financiamento adequado e suficiente, esse é um fator que compromete de forma contundente a realização das ações no âmbito municipal.

Além disso, esses relatos reforçam a importância de considerar as capacidades dos governos para sua implementação, especialmente as relacionadas aos aspectos cognitivos acerca da política (Lima e D'Ascenzi, 2013). Há uma fala que ilustra isso: "a gestora, apesar de ser assistente social, não foi 'preparada' para a gestão financeira" (Entrevistada 8). Ou seja, esses dois aspectos evidenciam a falta de qualificação de pessoas-chave, o que nos remete a outro fator associado: os participantes salientaram, principalmente, os problemas relacionados ao planejamento e aos gastos. Os equívocos na formulação do orçamento que impediram a realização de gastos foram relatados recorrentemente. A conclusão é inequívoca: se não há qualificação, inclusive nos postos-chave ocupados por dirigentes públicos, e há alta rotatividade, não haverá planejamento.

Em relação aos gastos, os entrevistados destacaram uma segunda dificuldade recorrente: os processos licitatórios e de compras. Esse quadro se agrava ainda mais naqueles municípios cuja posição geográfica faz com que os processos de aquisição de materiais gastem meses para se concretizar, o que leva a que pagamentos sejam feitos em ano subsequente. Isso é ainda mais contundente em municípios predominantemente rurais e da região Norte, pois a morosidade dos processos e o retrabalho nas compras geram um gasto bem maior do que o inicialmente previsto. No entanto, para além das especificidades daquela região, as limitações da burocracia em lidar com os processos licitatórios são não só recorrentes, mas aparecem como obstáculo real colocado por praticamente todos os municípios de pequeno porte, cujos processos licitatórios abarcam várias secretarias municipais. Esse cenário, aliado à rotatividade e à baixa qualificação dos profissionais envolvidos na política, mostra a centralidade da experiência na gestão. Um profissional treinado que sai de sua função implica a incerteza e a demora nos próximos processos, a depender do perfil de quem irá substituí-lo. Alguns técnicos relataram, por exemplo, que há pessoas que ficam três meses e depois saem, dificultando até mesmo a eficácia dos treinamentos. Observa-se, portanto, que, mesmo se tratando de orçamento, na prática são problemas de RH.

A terceira maior dificuldade apontada pelos entrevistados estava relacionada à utilização e ao preenchimento dos diversos sistemas de informação do Suas. A alimentação dos dados nos sistemas estava sendo feita, geralmente, por uma pessoa designada pelo gestor para essa função. Só em três municípios as informações eram incluídas por coordenadores de Cras/Creas diretamente. Nesse processo, destacaram como principais óbices: a negligência por parte de profissionais responsáveis por incluir os dados no

\footnotetext{
${ }^{9}$ No que diz respeito à gestão da política, há que se destacar algo que apareceu sistematicamente nos grupos focais, mas que nas entrevistas havia entrado apenas marginalmente: naqueles grupos foi destacado que um dificultador é a pouca compreensão também do prefeito quanto à assistência social e suas especificidades.
} 
sistema (contadores e técnicos responsáveis), o tempo necessário para o preenchimento e os contratempos quanto ao acesso e/ou perda de conexão com a internet (especialmente na região Norte, onde alguns gestores e/ou técnicos se deslocavam até a capital para inserir dados em lan-house). Além disso, especificidades não são consideradas, como as relativas a culturas indígenas, nas quais não se permite que os filhos menores de 6 anos sejam cuidados por outras pessoas que não suas famílias/comunidades.

\section{Ampliando as vozes}

As percepções de gestores e técnicos informadas nas entrevistas e grupos focais fundamentaram um conjunto de questões formuladas para o survey. Além disso, uma das estratégias na formulação do questionário foi a elaboração de questões com respostas abertas, gerando a manifestação mais qualitativa e descritiva dos problemas (importante ressaltar que todas essas questões tinham o máximo de espaço que a plataforma permitia). Os resultados não só reforçaram os achados iniciais, mostrando a sua representatividade para o território brasileiro, como trouxeram novos. Mais ainda, na maior parte das vezes pudemos notar que técnicos e gestores compartilhavam visões muito semelhantes sobre os problemas.

Quanto ao perfil dos 1.742 respondentes, a maioria tinha pouca experiência na área da assistência social, em média, 6,9 anos, apesar de o desvio muito grande, 6,4, ou seja, há aqueles que têm mais de uma década, mas há também muitos iniciantes, $42 \%$ tinham menos de cinco anos e $24 \%$, entre seis e dez anos. Os técnicos apresentavam um ano a mais na média de tempo de atuação do que os gestores ( 7,6 contra 6,6 anos). A atuação na assistência social no município a que estavam vinculados era, em média, de 5 anos, com um desvio de 5,2 anos. Interessante notar que 25,2\% dos respondentes já haviam trabalhado em outro município antes de ir para aquele no qual estavam vinculados e outros $9,9 \%$ faziam uma jornada dupla atuando em mais de um município ao mesmo tempo. Por fim, cabe dizer que $69 \%$ deles estavam ocupando funções de gestão e coordenação e $31 \%$ eram técnicos de nível superior exercendo atividades em diferentes setores.

Em relação à implementação da política de assistência social no município, 8,6\% consideraram que ela estava sendo implementada sem dificuldades, $45,4 \%$, com poucas dificuldades, $43,2 \%$, com muitas dificuldades e $2 \%$ disseram que ainda não havia sido implementada. O fato de $88,6 \%$ ressaltarem dificuldades no processo reforçou a importância do nosso objeto de estudo. Os técnicos foram um pouco menos positivos em relação aos gestores, 4,1\% contra 10,7\% consideram que estava sendo implementada sem dificuldades. E a diferença é de 10 pontos percentuais na categoria "com poucas dificuldades". Se, por um lado, os dados já conhecidos do censo Suas revelam a expansão e o alcance do Suas desde sua implantação, por outro, eles alertam para o fato de que existem dificuldades nesse processo. Em relação à natureza dessas dificuldades, pedimos 
aos respondentes para hierarquizar, por relevância, as seguintes opções: fatores de ordem financeira, técnica, administrativa e política, caso eles os vissem como problemas. Para fins analíticos, agregamos os dados relativos às categorias técnica e administrativa.

A primeira e maior dificuldade citada para o processo de implementação da política no município são os fatores financeiros $(48,7 \%)$. No entanto, em todos os casos o segundo fator informado como dificultador da implementação são questões administrativas e técnicas e figuram com 30,3\% no primeiro lugar, com 50,9\% no segundo e, no terceiro, com $45,8 \%$ das respostas. O Gráfico 4 mostra, em perspectiva comparada, as respostas quanto ao primeiro, segundo e terceiro fatores considerados como maiores problemas enfrentados. Observa-se que o fator financeiro é colocado como o primeiro, mas a presença de problemas técnicos e administrativos é massiva. Cabe ressaltar que, quanto à primeira dificuldade encontrada nesse processo, $37,8 \%$ dos técnicos afirmam que ela seja de ordem financeira contra $54,1 \%$ dos gestores. Nos demais, a semelhança na percepção dos dois grupos é muito grande, às vezes variando em décimos de percentual ou, no máximo, com uma margem de quatro pontos percentuais.

\section{Gráfico 4 \\ Principais dificuldades para a implementação da Assistência Social nos municípios na percepção dos respondentes (\%)}

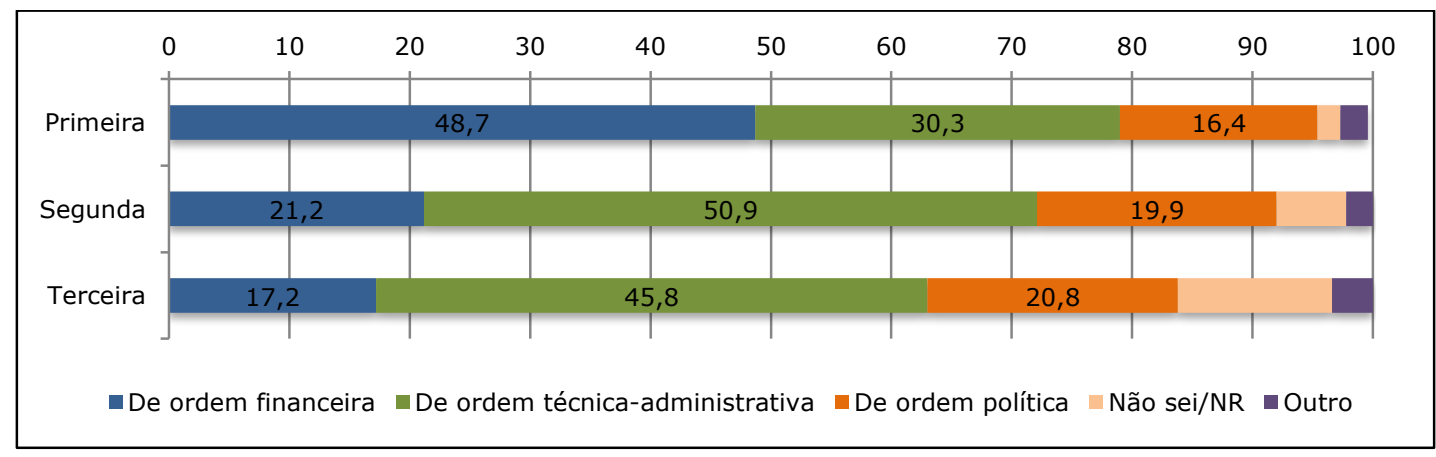

Fonte: Elaboração própria a partir dos dados citados.

No que se refere ao porte populacional, as dificuldades de ordem financeira são determinantes e aparecem em primeiro lugar independentemente de qual seja o tamanho do município, mas problemas técnicos e administrativos têm predominância em todos os demais cenários. Ou seja, o aspecto financeiro pode travar um processo, mas o papel massivo, mesmo que secundário, daqueles que têm relação direta com a gestão da política local é, sem dúvida, uma questão a ser ressaltada. 
Gráfico 5

Principais dificuldades para a implementação da Assistência Social conforme porte dos municípios na percepção dos respondentes (\%)

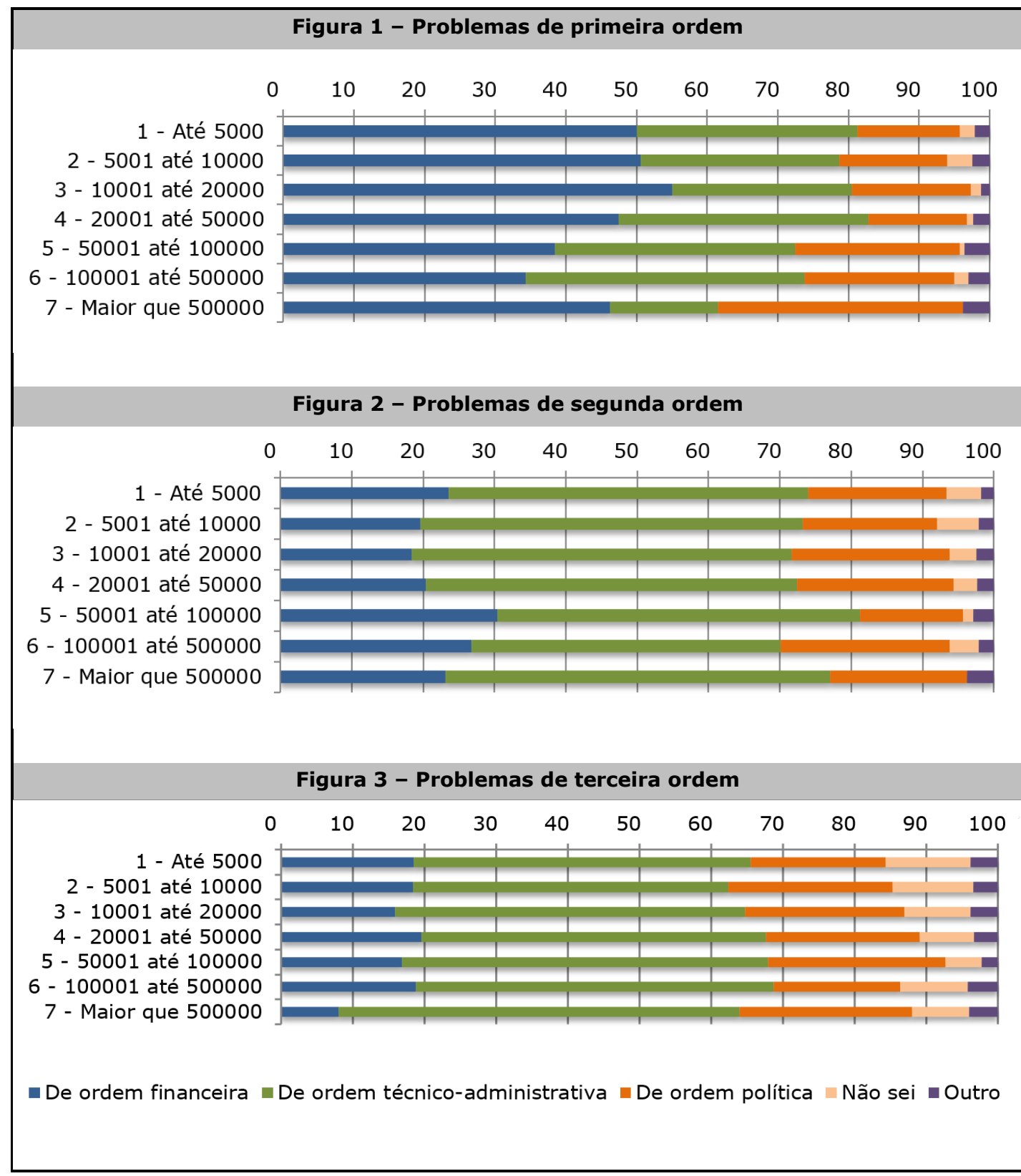

Fonte: Elaboração própria a partir dos dados citados. 
É necessário dizer que utilizamos da não execução, total ou parcial, do recurso advindo do MDS como um problema real de gestão, a partir do qual os respondentes se manifestavam. A estratégia foi respaldada no trabalho de Sátyro e Cunha (2018), que usam este como um indicador de baixa capacidade burocrática. A justificativa é que esse é um orçamento em que o gestor local tem bastante liberdade de gasto e irá obter dividendos eleitorais, portanto, não há motivo para a não execução exceto pelos entraves burocráticos e administrativos locais.

Perguntados se e quanto o município havia executado do recurso federal, 38,39\% disseram que estava totalmente executado, 48,4\%, mais da metade executado, $3 \%$, exatamente a metade, 9,45\%, menos da metade, e 0,93\%, não foram executados. Aqui a diferença entre técnicos e gestores é bastante expressiva: gestores respondem que foi executado em torno de 20 pontos percentuais mais do que os técnicos; $38,4 \%$ dos técnicos responderam que não tinham informação sobre isso contra $16,6 \%$ dos gestores. Em relação à parcialidade da execução ou à não execução, dos 860 respondentes, 424 se dispuseram a qualificar o porquê da não execução: 19,8\% relataram problemas de gestão ou relativos ao gestor, 22,64\% citaram problemas de licitação, 5,42\% aludiram diretamente ao contador, $28,77 \%$ responderam que se tratava de problemas burocráticos, técnicos ou administrativos e 20,05\% afirmaram tratar-se de problemas de recursos, orçamentários ou financeiros. Especificamente em relação ao contador, cabe ressaltar que esses $5,42 \%$ são os dados das questões abertas. No entanto, $42,1 \%$ dos respondentes disseram que o município contava com um escritório de contabilidade externo à prefeitura e $63,6 \%$ sabiam que ele prestava serviços também para outros municípios, o que mostra um alto potencial de contaminação do problema.

Os dados do survey quanto às principais dificuldades reforçam as informações colhidas nas entrevistas e grupos focais. Quanto aos dificultadores de ordem administrativa, 55,6\% consideraram que havia problemas na gestão que comprometiam a entrega de todos os serviços que poderiam ser prestados à população nos seus municípios. Dentre eles, destacaram os relacionados aos recursos humanos para a área: $76,5 \%$ dos respondentes consideraram que há um número insuficiente de trabalhadores (sendo nesse item apenas de seis pontos percentuais mais alta a percepção entre os técnicos), 66,5\% viam a alta rotatividade como um problema (há aqui sete pontos percentuais de diferença entre técnicos e gestores, com os primeiros ressaltando maior rotatividade), inclusive com a informação de que $35,1 \%$ dos respondentes trabalhavam em outro município que não o de origem. Soma-se a isso o fato de que $56,8 \%$ destacaram a baixa qualificação desses trabalhadores, o que pode explicar a opinião de $57,3 \%$ dos respondentes de que os processos de trabalho podem ser travados em razão da vontade de um técnico ou da vontade de uma pessoa de perfil político (na opinião de $56 \%$ ); aqui a diferença praticamente some entre os grupos.

Esse aspecto está diretamente relacionado à incapacidade de execução orçamentária ou de planejamento dos gastos na assistência social. É importante ressaltar 
que $42 \%$ informaram que o município contava com a assessoria de algum escritório de contabilidade ou um contador externo para orientar quanto à utilização dos recursos e repasses financeiros da assistência social. Destes, 63,6\% informaram que o escritório de contabilidade ou o contador externo também prestavam serviços para outros municípios, criando uma rede. Isso é um complicador na medida em que 50,1\% consideraram que o contador dificulta o planejamento e a execução da política municipal em razão do seu desconhecimento da área, inclusive havendo a informação de $26,8 \%$ dos respondentes de que, em razão de não compreenderem como incluir os recursos da área na Lei Orçamentária, já ocorreu a não utilização destes. As respostas a seguir ilustram alguns desses achados:

Falta de conhecimento do setor de planejamento e contabilidade (...). Por outro lado, quando digo deficiência técnica, digo com relação a dificuldades dos contadores do município entender as minhas necessidades orçamentárias. De 2014 em diante tem sido mais prático, levei inclusive um contador e o prefeito no Capacita Suas em Brasília, para juntos estarmos alinhados nas minhas necessidades (secretário, município de médio porte, MG).

(...) Impedimento ou morosidade do setor de compras, de licitação a tempo e hora, secretário da Fazenda interferindo ou até mesmo proibindo determinadas coisas. Contador nem é bom falar, é muito desgaste para realizar trabalhos na área com a falta de conhecimento destes profissionais em relação à política de assistência social (secretário, município de pequeno porte 2, MG).

(...) são uma série de questões: número de profissionais insuficiente; falta de conhecimento da política de assistência social pelo contador, finanças, prefeito, gestor, coordenador, técnicos; falta de habilidade para atuar como técnico; falta de interesse dos técnicos em se dedicar, acredito que pelo fator motivacional; má gestão; questões políticas (coordenador de Cras/Creas/Centro Pop, município de pequeno Porte 1, MG).

(...) O planejamento da gestão trava no setor de compra e/ou contabilidade por não ser prioridade nas licitações e/ou por desconhecimento do técnico responsável por esses setores (secretário, município de pequeno porte 2, MG, grifo do respondente).

Sem dúvidas, o desconhecimento de técnicos e de políticos acerca das especificidades da assistência social aparece como fator relevante para entender os problemas na ponta, estejam relacionados ao contador, aos dirigentes ou aos técnicos. Muitas foram as associações com a palavra "desconhecimento", desde "desconhecimento da política", de "como utilizar a verba, inclusive receio de fazer errado", "de utilização dos recursos, 'travamento' de processos licitatórios", da "PNAS e sua execução financeira", até 
aqueles que tentaram enfatizar o quanto a falta de preparo era generalizada: "desconhecimento de como gastar a verba do Paefi, desconhecimento do contador, desconhecimento do controle interno, desconhecimento da assessoria contratada pela prefeitura" (respostas de diferentes respondentes oriundas de diversos estados).

Diante disso, compromete-se a capacidade de planejamento, e os respondentes enfatizaram que fatores relacionados ao planejamento orçamentário-financeiro e aos processos de compras têm sido dificultadores para a implementação da política. As citações seguintes evidenciam a gravidade da ausência de qualificação e, por conseguinte, de planejamento:

O principal motivo (até 2013) era não constar na previsão orçamentária do município os recursos para serem reprogramados em suas respectivas fichas. A falta deste planejamento, juntamente com o desconhecimento, ou seja, a falta de capacitação dos gestores anteriores, fez com que a verba fosse ficando aglomerada e a prestação de serviços prejudicada, e ainda o município estrangulado, pois tudo caía para que fosse bancado com recursos próprios. Somente neste ano é que estou conseguindo remanejar o orçamento do município para criar fichas e fontes pertinentes.

(...) Falta de conhecimento técnico por parte da secretaria da Fazenda/Tesouraria, dificuldades com o setor de licitação/compras e insegurança da própria gestão em administrar os recursos (...) (secretário, município de pequeno porte $1, M G$ ).

Como pode ser visto nesse percurso exploratório, o processo de licitação está no centro das dificuldades, tendo aparecido em $22,64 \%$ dos casos, assim como as dificuldades com o planejamento, que ficam evidentes nas seguintes respostas:

(...) Primeiro fator primordial é o limite orçamentário. Na elaboração do orçamento, a secretaria de Planejamento libera uma cota orçamentária que abrange só o valor financeiro que virá para aquele ano, ficando, portanto, o saldo financeiro na conta sem orçamento, ou seja, tenho financeiro e não tenho orçamento. Para tentar solucionar vamos suplementando o máximo que dá. O segundo fator é a morosidade do setor de compras, demora mais tempo do que a Lei de Licitação prevê e penso que, por estar centralizado na prefeitura, o setor de compras prioriza outras políticas (diretor/coordenador de PSB/PSE/Vigilância, município de médio porte, MG).

(...) Primeiramente, grande parte dos recursos nem entraram em conta ainda. Segundo, falta de planejamento por parte da Gestão Municipal (técnico da gestão, município de pequeno porte $1, \mathrm{PR}$ ). 
(...) Reprogramações de recursos de anos anteriores. Dificuldades com o seguimento dos processos licitatórios. Falta de conhecimento de alguns contadores quanto à destinação dos recursos. Limitação da destinação dos recursos cofinanciados, sendo que a maioria só pode ser gasta com o custeio. [o problema estava na] falha da comunicação entre a secretaria de Assistência, o setor de compras e a secretaria de Fazenda (secretário, município de pequeno porte $2, M G$ ).

Essas evidências quanto ao "desconhecimento" como fator dificultador da implementação, associadas a um cenário de baixa qualificação e alta rotatividade, instigam-nos a pensar quais estratégias podem estar sendo utilizadas pelos municípios que informam conseguir gastar razoavelmente os recursos oriundos do MDS, conforme encontraram Sátyro e Cunha (2018). As entrevistas e grupos focais nos dão pistas de que há um investimento do interessado no processo, no sentido de abordar pessoalmente os responsáveis pelo planejamento ou pelas compras, principalmente quando se trata de um técnico-chave, e realizar um processo de convencimento. Isso porque, para que o processo ande, não só o conhecimento importa, mas também a comunicação e o cumprimento de prazos (por exemplo, a inserção das rubricas específicas da área só pode ser feita antes da votação legislativa, caso isso não ocorra, o processo fica para o próximo ano). Portanto, parece haver elementos informais relacionados às interações pessoais a ser considerados na análise, especialmente quando se tem a efetivação do planejamento e do gasto em contextos de fragilidades burocráticas.

Cabe também ressaltar o quanto os atrasos nos repasses apareceram como um problema primordial para os respondentes. Esse tema apareceu 20 vezes, o que corresponde a $4,7 \%$ das respostas abertas.

Também há uma preocupação do gestor municipal em reter um pouco de recursos, uma vez que os repasses destes recursos não são sempre assíduos (secretário, município de pequeno porte $1, \mathrm{MG}$ ).

Deixamos uma pequena reserva do IGD PBF $^{10}$ por causa dos atrasos de repasses (técnico, município de pequeno porte $2, \mathrm{MG}$ ).

Devido à necessidade de termos um fundo de reserva, pois os recursos não são repassados de forma regular e automática, porque há grandes atrasos referentes ao repasse de fundo a fundo (secretário, município de médio porte, $M G)$.

Cabe fazer uma diferenciação entre entrevistas e grupos focais e as perguntas abertas do survey. Nos primeiros, problemas relacionados às questões orçamentárias e

\footnotetext{
10 Índice de Gestão Descentralizada do Programa Bolsa Família.
} 
financeiras eram restritos à gestão. No entanto, no survey isso se estendeu para a falta de dinheiro efetivamente, seja pelo seu atraso, seja pela sua insuficiência.

Por fim, os resultados mostram que não se pode desconsiderar a importância de fatores de ordem política como interferentes na gestão dessa política pública. Em relação a eles, 29,6\% dos respondentes consideraram que são determinantes para a não implementação da política, se comparados aos fatores técnicos. Nessa direção, 83,8\% consideraram que o prefeito conhecia o Suas, $78,6 \%$, que o prefeito sabia da existência da PNAS e 58,2\% deles supunham que o prefeito conhecia as Nobs (Normas Operacionais Básicas). No entanto, paradoxalmente, apenas $29 \%$ consideraram que o gestor municipal de assistência social valorizava a política, o que incidia na sua implementação, assim como $45,9 \%$ dos respondentes entenderam que a assistência social não era uma política conhecida por outros técnicos, como o contador.

(...) O prefeito atual e o secretário não entendem nada sobre a política de assistência social e nem a necessidade de equipe técnica. Ele é a favor do assistencialismo. Por conta disso, o Cras não cumpre a sua função (coordenador de Cras/Creas/Centro POP, município de pequeno porte 1, MG).

Ao serem perguntados se havia forte influência de políticos (vereadores, deputados e outros) na política de assistência social, 31,6\% disseram que isso acontecia, 50,3\%, que isso acontecia pouco e 18,2\%, que isso não acontecia. Uma forma ainda existente, por exemplo, é quando um político apresenta uma lista de pessoas para se tornarem beneficiários de programa social: 14,2\% informam que isso acontecia sempre, 15,4\%, que acontecia muito, 39\%, que acontecia pouco e 31,4\%, que nunca acontecia (Gráfico 6):

\section{Gráfico 6 \\ Existência de tentativas diretas de influência de políticos na execução de ações da Assistência Social (\%)}

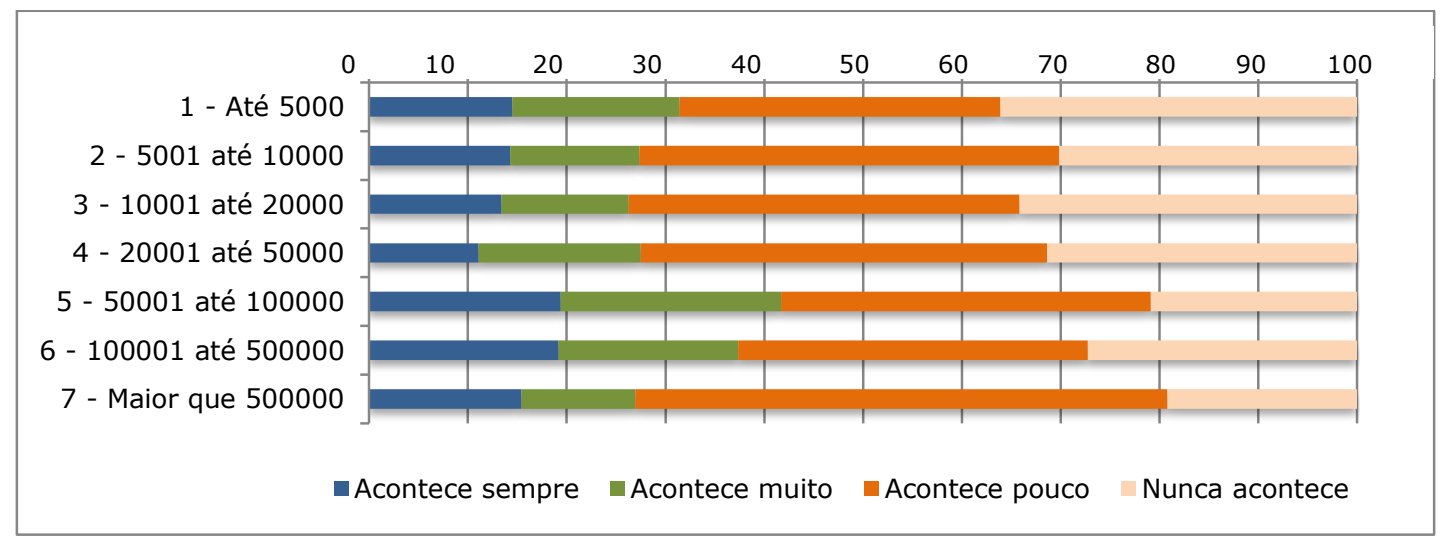

Fonte: Elaboração própria a partir dos dados citados. 
O Gráfico 6 ilustra bem a situação descrita anteriormente, a grande maioria reconhece que interferências diretas, como apresentação de listas de apadrinhamento, acontecem muito pouco ou já não acontecem mais em seus municípios. No entanto, se mais de $25 \%$ disseram que isso nunca acontecia, sendo que essa porcentagem chega a $36 \%$ nos municípios pequenos, ainda é relevante saber que cerca de um quarto (ou mais) dos municípios relatou que isso acontecia sistematicamente chegando a $41,7 \%$ nos municípios entre 50 e 100 mil habitantes e 37,9\% naqueles entre 100 e 500 mil habitantes. Ou seja, é interessante notar que isso acontecia numa escala maior nos municípios maiores, onde se espera uma maior capacidade burocrática.

Os dados e informações que o survey evidenciou acerca da implementação da política de assistência social no âmbito municipal não só reforçaram alguns achados das entrevistas e grupos focais, mostrando a sua representatividade para o território brasileiro, como suscitaram novos elementos para a melhor compreensão do processo de implementação da política e os fatores que o dificultam. Dentre eles, saltam aos olhos os relacionados à burocracia (em especial a que entregam os serviços), ao planejamento orçamentário-financeiro e sua execução (destacando o papel dos profissionais da contabilidade e o pouco conhecimento de gestores quanto ao tema) e à dimensão cultural (expressa nos problemas cognitivos revelados pelo que foi descrito como "desconhecimento" e na visão conservadora e/ou equivocada sobre a assistência social que rebate, inclusive, na forma como o orçamento é planejado). Por fim, cabe também ressaltar que, de forma geral, a percepção dos técnicos vai na mesma direção da dos gestores com diferenças de graus, que não são muito expressivas em boa parte dos dados.

\section{Daquilo que não foi perguntado, mas foi achado}

A pesquisa revelou nas entrelinhas aspectos que nos ajudam a entender melhor as interações no nível municipal, para além de identificar os entraves à implementação. Inicialmente, alguns relatos que nos pareceram secundários, mesmo que diretos, foram descortinando uma forma de lidar com os problemas. Durante as entrevistas e os grupos focais, e mesmo nas respostas abertas do survey, apareceu de forma sistemática (apesar de descrita de diversas formas) uma "necessidade de comunicação", seja "com os técnicos", "com o pessoal da contabilidade" ou "do financeiro". Donde se deduz a necessidade de arranjos informais e de interações no nível pessoal para a solução dos problemas levantados, bem como o papel da discricionariedade tratado anteriormente.

Para entender esse achado, utilizamos o conceito de práticas informais de Van Tatenhove, Mak e Liefferink (2006):

Nós definimos por práticas informais aquele conjunto de ações não codificadas do dia a dia, as interações relativas às questões da própria política pública, em que a participação dos atores, a formação de coalizões, o processo de agenda setting, as decisões preliminares e a implementação não são 
JOGANDO LUZES SOBRE OS DETERMINANTES BUROCRÁTICOS E DE GESTÃO DA POLÍTICA DE ASSISTÊNCIA SOCIAL

estruturadas por regras ou instituições formais previamente estabelecidas ${ }^{11}$

(Van Tatenhove, Mak e Liefferink, 2006, p. 17 - livre tradução dos autores).

Trata-se de arranjos formais e informais de que os atores lançam mão para alcançar seus objetivos quando na interação com outros atores para o cumprimento das regras formais, gerando padrões baseados em sistemas simbólicos, esquemas cognitivos e modelos morais compartilhados (North, 1990; Ostrom, 1999; Hall e Taylor, 2003).

Um relato exemplifica o quanto a gestão pode depender de um indivíduo para andar com processos ou para travá-los. Nele pode-se ler que uma entrevistada (8), quando descobriu que havia recurso disponível para gastar, "foi atrás de aprender" como gastar o recurso e o porquê não havia sido gasto. Ela e outra técnica aprenderam sobre rubricas específicas para determinados gastos, fizeram proposta e enviaram para a gestora, que, por sua vez, encaminhou para o contador do município. No entanto, este, ao fechar a peça orçamentária, observou as rubricas novas e, como as desconhecia, "enxugou elas" na rubrica principal, "na 150 ", e enviou a peça assim. Somente depois da lei votada é que elas descobriram o que havia acontecido. Dessa forma, outro ano se passou sem que se pudesse executar o recurso. Elas foram diretamente ao contador para explicar o ocorrido, bem como as especificidades daquela política. Só assim, já no terceiro ano, a verba pôde ser executada. Observa-se como foi necessária uma comunicação estreita entre diferentes técnicos, com a utilização de estratégias informais para o cumprimento das regras formais. Outras falas reforçam a existência de problemas em relação ao contador: "o planejamento da gestão trava no setor de compras e na contabilidade por não ser prioridade nas licitações e/ou por desconhecimento do técnico responsável" (Entrevistada 4) ou "o setor de contabilidade tem dificuldades em realizar as despesas conforme a orientação do MDS" (Entrevistada 11).

Outro exemplo importante para clarear tais achados é que uma entrevistada (12), ao ser confrontada com o fato de que os dados de Sátyro, Cunha e Campos (2016) mostravam que a burocracia mais weberiana do Sul executava menos os recursos federais remetidos aos municípios do que a burocracia mais precarizada do Nordeste, respondeu prontamente ser muito provável que no Sul eles sigam todos os trâmites burocráticos, o que torna o processo mais lento, enquanto no Nordeste eles devem resolver usando "outros meios" que permitem encurtar o processo. Com o material analisado podemos sugerir que esses "outros meios" sejam considerados arranjos informais para solução de problemas que possibilitariam a execução dos recursos, ainda que dentro das regras formais. Isso nos remete às ideias de Lima e D'Ascenzi (2013), que tratam a implementação como resultante da interação entre a intenção do plano formalizado inicialmente e o contexto local. Ou seja, há um encadeamento de ações e interações de vários atores intencionados (Lotta e Pavez,

11 "We define informal practices above as those non-codified setting of day-to-day, interaction concerning policy issue, in which the participation of actors, the formation of coalitions, the processes of agenda setting, (preliminar) decision making and implementation are not structured by pre-given sets of rules or formal institutions". 
2010), ou seja, que agem visando a determinados fins que não seriam alcançados sem inserções informais. Com base nisso podemos sugerir reflexões sobre os resultados encontrados por Sátyro, Cunha e Campos (2016), que apontam para mais execução orçamentária em lugares com menor capacidade burocrática weberiana. A hipótese que poderíamos levantar é de que isso possa ser explicado por tais arranjos. Diante da percepção da necessidade e do julgamento feito por um determinado burocrata de rua quando Lipsky (1980) diz que os BNR utilizam de estratégias para lidar com as incertezas e pressões - de que algo tenha que ser feito para além das regras formais para a solução de um problema de implementação, lança-se mão de arranjos informais no intuito de dar continuidade a um determinado processo.

\section{Dos nossos achados, algumas considerações}

O estudo que deu origem a este artigo nos possibilitou explorar, por meio de diferentes técnicas, as opiniões de gestores e técnicos municipais de todo o Brasil, mais fortemente representados pelo estado de Minas Gerais, acerca dos fatores que consideram relevantes para a implementação da política de assistência social. Os problemas sistemáticos que aparecem em destaque são basicamente relativos a questões técnicas e administrativas - donde se lê recursos humanos em várias dimensões - os de natureza financeiro-orçamentária, sendo acompanhados por dificuldades na produção de dados (o que também remonta aos recursos humanos) e pelas tentativas de ingerência política na política pública. E foi interessante notar que as percepções de técnicos e gestores locais são muito similares e estão sempre na mesma direção, mudando, no máximo, o seu grau.

É possível afirmar a centralidade das características gerais da burocracia municipal para a efetivação da gestão e da entrega dos serviços: há insuficiência numérica de pessoal e flutuação e rotatividade do quadro de funcionários em razão dos tipos de vínculos e dos baixos salários. Além disso, essa burocracia percebe-se pouco capacitada para atuar em uma política nova e menos central. Esse primeiro conjunto nos remete diretamente à estrutura administrativa e sua incapacidade para o planejamento orçamentário-financeiro, inclusive na garantia da sua execução (por algum tempo) em muitos municípios (Sátyro, Cunha e Campos, 2016). Relativo a esse último aspecto, revela-se que o desconhecimento, por parte de contadores e de gestores, das normativas que regulam a política de assistência social e que produziram mudanças legais específicas tem gerado dificuldades e resistências à sua implementação conforme o delimitado normativamente. Esses achados podem parecer triviais para quem já conhece a política ou trabalha com implementação há algum tempo, no entanto, o que se agrega com este artigo é o conhecimento de que, de fato, isso é determinante (como havia surgido na abordagem qualitativa), espraia-se pelo território nacional, mostrando o quanto é sistemático (como identificado no survey) e generalizável, e mais, que técnicos e gestores apontam na mesma direção, o que fortalece ainda mais os achados. 
JOGANDO LUZES SOBRE OS DETERMINANTES BUROCRÁTICOS E DE GESTÃO DA POLÍTICA DE ASSISTÊNCIA SOCIAL

Soma-se a isso o fato de que municípios de pequeno porte informam inúmeros problemas para procederem ao gasto, dadas as regras para compras públicas que não consideram as diferentes realidades municipais e mesmo regionais (por exemplo, o fator amazônico) e fazem as mesmas exigências para município com 2.000 ou 2.000.000 de habitantes, com PIBs diferenciados e capacidades burocráticas completamente diversas. No entanto, constatamos que isso não é prerrogativa dos municípios de pequeno porte. As declarações mostram um padrão que coloca os limites financeiro-orçamentários como determinantes para todos os portes de município, mas os problemas de natureza técnica e administrativa são os que minam a política no dia a dia. E os resultados sugerem que podemos pensar isso para outras políticas implementadas por BNR. Dentro disso há uma miríade de fatores, desde os problemas com a licitação até o atraso no repasse das verbas, mas o que sai dos relatos é que quase todos se originam do desconhecimento das regras formais por parte de algum técnico ou gestor, consequência das características tratadas acima. E mais, as falas sugerem que a solução comumente utilizada - capacitação - é limitada, pois não resolve a alta rotatividade e a pouca permanência em determinados cargos.

Por fim, o artigo apontou para a existência de arranjos informais na solução dos entraves na implementação que demandam uma agenda de pesquisa importante. Considerar que a implementação de uma política pública é processo complexo e dinâmico e que vários fatores podem incidir no seu êxito é assumir que os estudos sempre poderão deixar de lado algum aspecto apontado como relevante pela literatura. E nos parece que essa categoria analítica (arranjos informais) tem um papel importante no entendimento da variação dos processos nos níveis municipais que pode ir além do caso da assistência social aqui analisado. Podemos concluir que o foco na burocracia e a abordagem utilizada nos possibilitaram observar que há características que são relevantes quando se consideram os arranjos e as estratégias que são utilizados para a efetivação da política. Sendo uma pesquisa exploratória, nosso intuito foi construir conhecimentos que possam vir a orientar outros estudos futuramente.

\section{Referências bibliográficas}

BRODKIN, E. Z. "Bureaucracy redux: management reformism and the welfare state". Journal of Public Administration Research and Theory, n 17, 2007.

"Policy work: street-level organizations under new managerialism". Journal of Public Administration Research and Theory, no 21, 2011.

CAVAlCANTE, P.; LotTA, G. (orgs.). Burocracia de médio escalão: perfil, trajetória e atuação. Brasília: Enap, 2015.

Cavalcante, P.; Ribeiro, B. "O Sistema Único de Assistência Social: resultados da implementação da política nos municípios brasileiros". Revista de Administração Pública, Rio de Janeiro, vol. 46, nº 6, 2012. 
CHRISTIANSEN, T.; PiATTONI, S. (eds.). Informal governance in the European Union. Cheltenham: Edward Elgar Publishing, 2003.

Collins, R.; MAKowsky, M. The discovery of society. Singapura: McGraw-Hill, 1988.

Couto, B., et al. (orgs.). Sistema Único de Assistência Social no Brasil: uma realidade em movimento. São Paulo: Cortez Editora, 2017.

D'AlbUQUERQUE, R. W. "A demanda por serviços socioassistenciais e a burocracia da assistência social dos municípios brasileiros". Dissertação de mestrado em Ciência Política. UFMG, Belo Horizonte (MG), 2017.

DE BONIS, D.; PACHECO, R. Nem político, nem burocrata: o debate sobre o dirigente público. In: ABRUCio, F.; LOUREIRO, M. R.; PACHECO, R. (orgs.). Burocracia e política no Brasil: desafio para o Estado democrático no século XXI. Rio de Janeiro: Editora da Fundação Getúlio Vargas, vol. 1, p. 273-295, 2010.

DYE, T. D. Understanding public policy. Englewood Cliffs, N.J.: Prentice-Hall, 1984.

EIRÓ, F. "Programa Bolsa Família e os pobres "não merecedores": poder discricionário e os limites da consolidação de direitos sociais". Boletim de Análise Político-Institucional, Brasília, Ipea, n 13, p. 65-70, 2017.

ELMORE, R. F. Diseño retrospectivo: la investigácion de la implementación y las decisiones políticas. In: VAN METER, D. S., et al. (dirs.). La implementación de las políticas. México: Miguel Angel Porrua, 1996.

FARIA, C. A. P. (org.). Implementação de políticas públicas: teoria e prática. Belo Horizonte: Ed. PUC Minas, 2012.

GLASER, B. G. Theoretical sensitivity: advances in the methodology of grounded theory. Mill Valley, CA: Sociology Press, 1978.

Gofen, A. "Mind the gap: dimensions and influence of street-level divergence". Journal of Public Administration Research and Theory, n० 24, 2014.

HALL, P. A.; TAYLOR, R. C. R. "As três versões do neo-institucionalismo". Lua Nova, São Paulo, no 58, p. 193-223, 2003.

HiLl, M. Implementação: uma visão geral. In: Saravia, E.; FerRarezi, E. (orgs.). Políticas públicas. Brasília: Enap, 2006.

HOWLETT, M.; RAMESH, M. Studying public policy: policy cycles and policy subsystems. Oxford: Oxford University, 1995.

HUPE, P. "What happens on the ground: persistent issues in implementation research". Public Policy and Administration, vol. 29, n 2, 2014.

KING, G.; KEOHANE, R.; VERBA, S. Designing social inquiry: scientific inference in qualitative research. Princeton University Press, 1994.

LASSWELL, H. A pre-view of policy sciences. New York: American Elsevier, 1971.

LIMA, L. L.; D'ASCENZI, L. "Implementação de políticas públicas: perspectivas analíticas". Revista de Sociologia e Política, vol. 21, no 48, p. 101-110, dez. 2013.

Estrutura normativa e implementação de políticas públicas. In: MADEIRA, L. M. (org.). Avaliação de políticas públicas. Porto Alegre: UFRGS/Cegov, p. 50-64, 2014.

. "O papel da burocracia de nível de rua na implementação e (re)formulação da política nacional de humanização dos serviços de saúde de Porto Alegre (RS)". Revista de Administração Pública, vol. 1, no 51, p. 46-63, 2017. 
LIMA, L. L., et al. "Burocracia e políticas públicas: a implementação da política nacional de humanização dos serviços de saúde em Porto Alegre (RS)". Revista do Serviço Público, Brasília, vol. 65, no 4, p. 493-515, out.- dez. 2014.

LIMA, P. P. F. "Implementação como interpretação e aprendizado: sobre a implementação das averiguações cadastrais no Cadastro Único de Programas Sociais". Boletim de Análise PolíticoInstitucional (Ipea), no 13, p. 59-64, out. 2017.

LIPSKY, M. Street-level bureaucracy: dilemmas of the individual in public services. New York: Russel Sage, 1980.

LOTTA, G. S. O papel das burocracias do nível de rua na implementação de políticas públicas: entre o controle e a discricionariedade. In: FARIA, C. A. (org.). Implementação de políticas públicas: teoria e prática. Belo Horizonte: Editora PUC Minas, p. 20-49, 2012.

"Agentes de implementação: uma forma de análise de políticas públicas". Cadernos Gestão Pública e Cidadania, São Paulo, vol. 19, no 65, p. 186-207, jul.-dez. 2014.

LOTTA, G. S.; PAVEZ, T. R. "Agentes de implementação: mediação, dinâmicas e estruturas relacionais". Cadernos Gestão Pública e Cidadania, São Paulo, vol. 15, nº 56, p. 109-126, 2010.

LotTA, G. S.; PereirA, G. N.; Bichir, R. M. "Implementação de políticas públicas no nível intramunicipal: o caso das supervisões de assistência social da cidade de São Paulo". Revista Brasileira de Políticas Públicas e Internacionais, vol. 3, no 1, p. 286-311, 2018.

LOTTA, G. S.; PIRES, R. R. C.; OliveirA, V. E. "Burocratas de médio escalão: novos olhares sobre velhos atores da produção de políticas públicas". Revista do Serviço Público, vol. 65, no 4, p. 407 437, out.-dez. 2014

LowI, T. "American business, public policy, case studies and political theory". World Politics, vol. 16, p. $677-715,1964$

LOWNDES, V. Institutionalism. In: MARSH, D.; STOKER, G. (eds.). Theory and methods in political science. Palgrave: Red Globe Press, 2002.

LYNN, L. E. Designing public policy: a casebook on the role of policy analysis. Santa Monica, California: Goodyear, 1980.

MAHONEY, J.; GOERTZ, G. "A tale of two cultures: contrasting quantitative and qualitative research". Political Analysis, vol. 14, no 3, 2006.

MAJONE, G.; Wildavsky, A. Implementation as evolution. In: Pressman, J. L.; WildavskY, A. (orgs.). Implementation. California: University of California Press, p. 163-180, 1984

MAY, P. J.; WINTER, S. C. "Politicians, managers, and street-level bureaucrats: influences on policy implementation". Journal of Public Administration Research and Theory, no 19, 2009.

MeAD, L. M. "Public policy: vision, potential, limits". Policy Currents, fev. n 1-4. 1995.

NAtAlino, M. A. C. "Percepções de burocracias locais sobre o Sistema Único de Assistência Social". Boletim de Análise Político-Institucional (Ipea), no 13, p. 51-58, out. 2017.

NORTH, D. C. Institutions, institutional change and economic performance. Cambridge: Cambridge University Press, 1990.

OliveirA, V.; ABRÚcio, F. Burocracia de médio escalão e diretores de escola: um novo olhar sobre o conceito. In: PIRES, R.; LOTTA, G.; OLIVEIRA, V. Burocracia e políticas públicas no Brasil: interseções analíticas. Brasília: Instituto de Pesquisa Econômica Aplicada (Ipea), 2018.

Ostrom, E. An assessment of the institutional analysis and development framework. In: SABATIER, P. (ed.). Theories of the policy process. Boulder: Westview Press, 1999.

PIRES, R. R. C. "Burocracia, discricionariedade e democracia: alternativas para o dilema entre controle do poder administrativo e capacidade de implementação". Cadernos de Gestão Pública, São Paulo, vol. 14, no 54, p. 141-180, 2009. 
. "Sociologia do guichê e implementação de políticas públicas". Revista Brasileira de Informação Bibliográfica em Ciências Sociais - BIB, São Paulo, no 81, p. 5-24, 2017.

Pires, R. R. C.; Gomide, A. A. Burocracia, democracia e políticas públicas: arranjos institucionais de políticas de desenvolvimento. Brasília: Instituto de Pesquisa Econômica Aplicada (Ipea), 2014.

RICE, D. "Street-level bureaucrats and the welfare state: toward a microinstitutionalist theory of policy implementation". Administration and Society, vol. 45, no 9, p. 1.038-1.062, 2012.

SABATIER, P. A.; MAZMANiAn, D. A. La implementácion de la política pública: un marco de análisis. In: VAN METER, D. S., et al. (dirs.). La implementación de las políticas. México: Miguel Angel Porrua, 1996.

Saravia, E.; Ferrarezzi, E. (orgs.). Políticas públicas. Brasília: Enap, 2006.

SÁTYRo, N.; CUNHA, E. "A capacidade transformativa do governo federal brasileiro na construção de uma burocracia da assistência social nos municípios". Revista de Administração Pública, Rio de Janeiro, vol. 52, no 3, 2018.

SÁTYRo, N.; CUNHA, E.; CAMPOS, J. "Análise espacial da burocracia da assistência social nos municípios brasileiros: notas para uma reflexão sobre a capacidade de implementação dessa política". Opinião Pública, Campinas, vol. 22, nº 2, 2016.

TORRES, H. G., et al. Educação na periferia de São Paulo: ou como pensar as desigualdades educacionais? In: RibeIRo, L. C. Q.; KAZTMAN, R. (orgs.). A cidade contra a escola: segregação urbana e desigualdades educacionais. Rio de Janeiro: Letracapital, p. 59-90, 2008.

VAn Meter, D. S.; VAn Horn, C. E. El processo de implementácion de las políticas. Un marco conceptual. In: VAN METER, D. S., et al. (dirs.). La implementación de las políticas. Ciudad del México: Miguel Angel Porrua, 1996.

VAn TATENhove, J.; MAK, J.; LiefFerinK, D. "The inter-play between formal and informal practices". Perspectives on European Politics and Society, vol. 7, no 1, p. 8-24, 2006.

WALT, G. Health policy: an introduction to process and power. London: Zed, 1994.

\section{Abstract \\ Casting a light on bureaucratic determinants and management of social welfare policy in Brazilian municipalities}

The existing empirical research is insufficient to explain the variation in bureaucratic and managerial capacity at the local level and its consequences for the implementation of social policies. This article analyzes the perception of technicians and municipal managers of social assistance regarding the problematic factors in the implementation of the policy. The research design uses grounded theory to generate knowledge about the field, as well as a survey, in an attempt to analyze how representative the qualitative findings are of the whole. The results show the centrality of budgetary constraints in policy implementation, but put at the center of the discussion technical and administrative factors such as the major stumbling blocks in managing social assistance policy at the local level. The results also suggest the use of informal strategies for solving problems of this nature.

Keywords: social assistance; street-level bureaucracy; grounded theory; implementation of social policies; bureaucratic ability

\section{Resumen}

Iluminando los determinantes burocráticos y de gestión de la política de asistencia social en los municipios brasileños

La investigación empírica conocida es insuficiente para explicar la variación en la capacidad burocrática y gerencial a nivel local y sus consecuencias para la implementación de políticas sociales. Este artículo 
analiza la percepción de los técnicos y gerentes municipales de asistencia social con respecto a los factores problemáticos en la implementación de la política. El diseño de la investigación utiliza la teoría fundamentada, porque el propósito es generar conocimiento sobre el campo y una encuesta, en le intento de analizar qué tan representativos son los hallazgos cualitativos del conjunto. Los resultados muestran la centralidad de las restricciones presupuestarias en la implementación de políticas, pero ponen en el centro de la discusión factores técnicos y administrativos como los principales obstáculos en la gestión de la política de asistencia social a nivel local. Los resultados también sugieren el uso de estrategias informales para resolver problemas de esta naturaleza.

Palabras clave: asistencia social; burocracia a nivel de calle; teoría fundamentada; implementación de políticas sociales; capacidad burocrática

\section{Résumé}

Éclairage sur les déterminants bureaucratiques et de gestion de la politique de protection sociale dans les municipalités brésiliennes

Les recherches empiriques connues sont insuffisantes pour expliquer la variation des capacités bureaucratiques et managériales au niveau local et ses conséquences pour la mise en œuvre des politiques sociales. Cet article analyse la perception des techniciens et des responsables municipaux de l'assistance sociale concernant les facteurs problématiques dans la mise en œuvre de la politique. La conception de la recherche utilise une théorie enracinée, car son objectif est de générer des connaissances sur le terrain et une enquête, dans le but d'analyser la représentativité des résultats qualitatifs dans leur ensemble. Les résultats montrent la centralité des contraintes budgétaires dans la mise en œuvre des politiques, mais mettent au centre de la discussion des facteurs techniques et administratifs tels que les principaux obstacles à la gestion de la politique d'assistance sociale au niveau local. Les résultats suggèrent également l'utilisation de stratégies informelles pour résoudre des problèmes de cette nature.

Mots-clés: assistance sociale; bureaucratie de rue; théorie enracinée; mise en œuvre de politiques sociales; capacité bureaucratique

Artigo submetido à publicação em 22 de dezembro de 2017. Versão final aprovada em 16 de julho de 2019.

Opinião Pública adota a licença Creative Commons CC-BY. 